\title{
Toxic Dilatation of the Colon in Granulomatous Colitis
}

\section{Report of 2 Cases}

\author{
John P. Papp, MD and H. Marvin Pollard, MD, FACP
}

Toxic dilatation of the colon associated with Crohn's disease (granulomatous colitis) is an uncommon and largely unrecognized complication. Its occurrence in ulcerative colitis is well recognized (1-2) and, on occasion, has been used as a point against the diagnosis of Crohn's disease (3).

Prior to 1966, Janowitz and Present (4) and Marshak et al (5) had not seen toxic dilatation of the colon in granulomatous colitis. However, Hawk and Turnbull (6) observed toxic dilatation in 14 of 87 surgically treated cases of granulomatous colitis. Unfortunately, they did not describe any of their 14 cases, but Farmer et al (7) in a subsequent report stated that of the 14 cases, 4 had granulomas on microscopic examination.

Schachter et al (8) were the first to report in detail a case they initially felt represented ulcerative colitis with toxic megacolon but which was subsequently diagnosed as granulomatous colitis. In 1968, McGovern and Goulston (9) reported the second case of toxic dilatation in granulomatous colitis.

We wish to report 2 additional patients, 1 of whom had two episodes of toxic dilatation after several years of disease.

From the Department of Internal Medicine (Section of Gastroenterology), The University of Michigan Medical Center, Ann Arbor, Mich.

Supported in part by Grant AM 05539, National Institutes of Health.

Address for reprint requests: J. Papp, MD, The University of Michigan Medical Center, Ann Arbor, Mich 48104.

\section{CASE REPORTS}

Case 1. ZG, a 19-year-old white male, was in excellent health until November 1967, when he began to have three to five loose brown bowel movements, both day and night. Intermittent, cramping abdominal pain was relieved by defecation. Seven months later, he experienced bright red rectal bleeding for the first time.

Physical examination showed a thin, lethargic male weighing $112 \mathrm{lb}$. He was afebrile. His abdomen was minimally tender to palpation in the left lower quadrant. No masses were present. Rectal examination showed no masses or tenderness, Friable, hyperemic and edematous mucosa was seen at lis $\mathrm{cm}$ on sigmoidoscopy. Biopsy of this area showed focal nonspecific inflammation with a single granulomatous focus.

Barium enema examination showed an abnormal mucosal pattern of the entire colon (Fig 1). Fdema and mucosal ulcerations were greater in the transverse and sigmoid colon. Ulceration and serration of the terminal ileal mucosa was seen upon reflux of barium. Examination of the upper gastrointestinal tract revealed mucosal irregularity of the terminal ileum and cecum.

Treatment with Azulfidine* and tincture of belladonna relieved the symptoms. By August 1968, the patient weighed $126 \mathrm{lb}$ and was having four to five bowel movements per day.

On Ficb 10, 1969, he became febrile $\left(101^{\circ} \mathrm{F}\right)$. and bowel movements increased to 15 per day. On admission to our hospital 4 days later, he appeared acutely ill. His blood pressure was $118 \mathrm{mmHg}$ systolic and $86 \mathrm{mmHg}$ diastolic, pulse rate was $116 / \mathrm{min}$, respiratory rate $20 / \mathrm{min}$, and he had an oral temperature of $102^{\circ} \mathrm{F}$. Examination of the abdomen showed moderate, lower abdominal tenderness. Bowel sounds were hypoactive.

Intermittent spiking fever $\left(103^{\circ} \mathrm{F}\right)$ and progressive abdominal distention occurred during the first 48 hr of hospitalization. Routine laboratory deter-

\footnotetext{
* Pharmacia Laboratories Inc, Piscataway, NJ.
} 


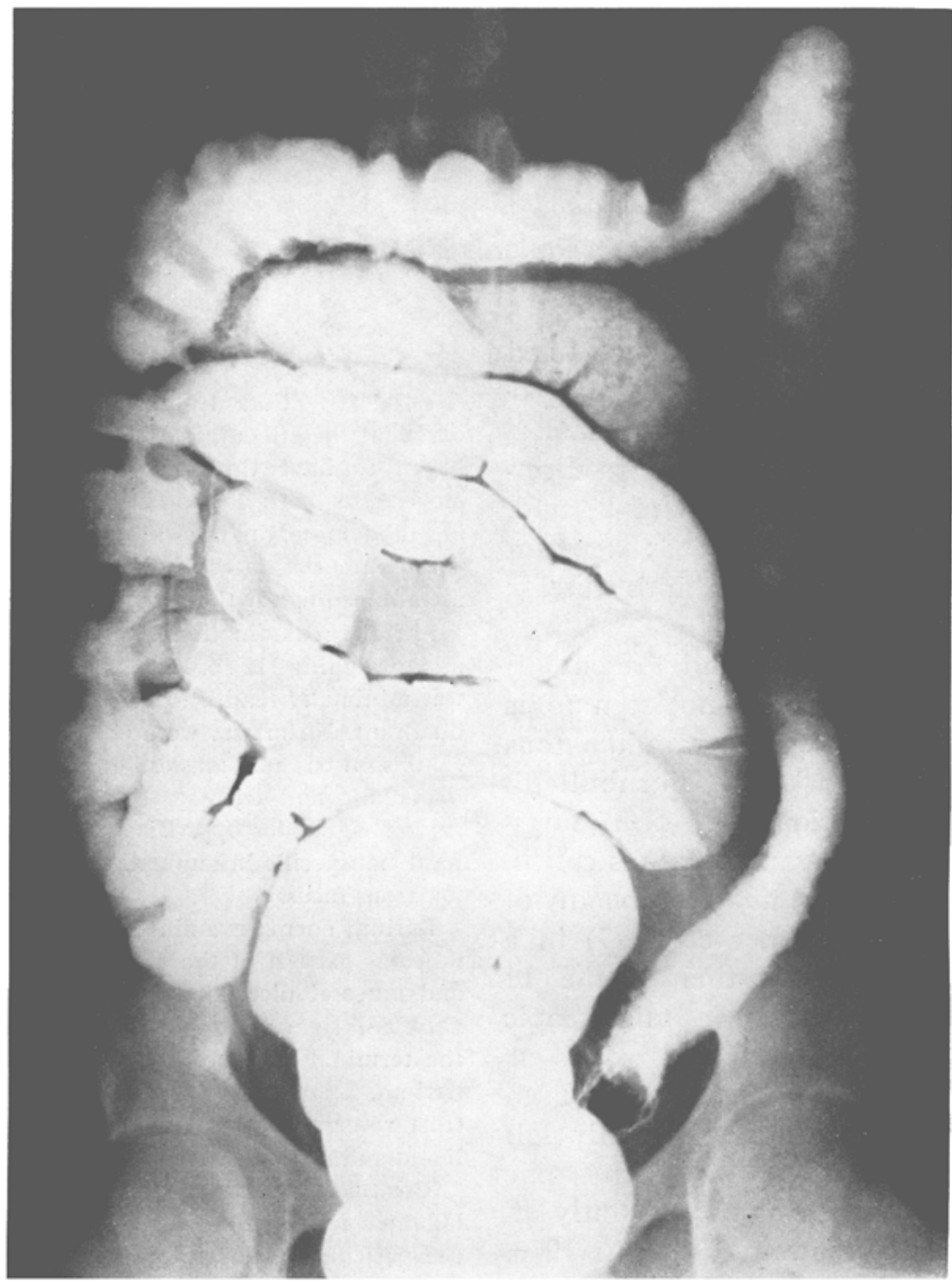

Fig 1. Abnormal mucosal pattern of entire colon is shown on barium enema examination. Mucosal ulcerations are prominently seen in transverse and sigmoid colon.

minations were unremarkable, except for a leukocrtosis of $20,000 / \mathrm{cu} \mathrm{mm}$ with a shift to the left. On the third hospital day, bowel sounds were absent and the patient was given intravenous Keflin,* and intramuscular kanamycin. A flat plate of the abdomen showed dilatation of the transverse colon and air in multiple loops of small bowel. One day later, a flat plate of the abdomen showed an

*Eli Lilly and Company, Indianapolis, Ind. increase in the diameter of the transverse colon and splenic flexure compatible with toxic megacolon (Fig 2). On the fifth hospital day, a subtotal colectomy, ileosomy and resection of 2 feet of terminal ileum was done.

Gross examination of the colon revealed linear and longitudinal ulcers with interspersed normal mucosa. Histologic examination of the colon showed extensive chronic inflammation with some fibrosis in the submucosa extending through the muscular- 


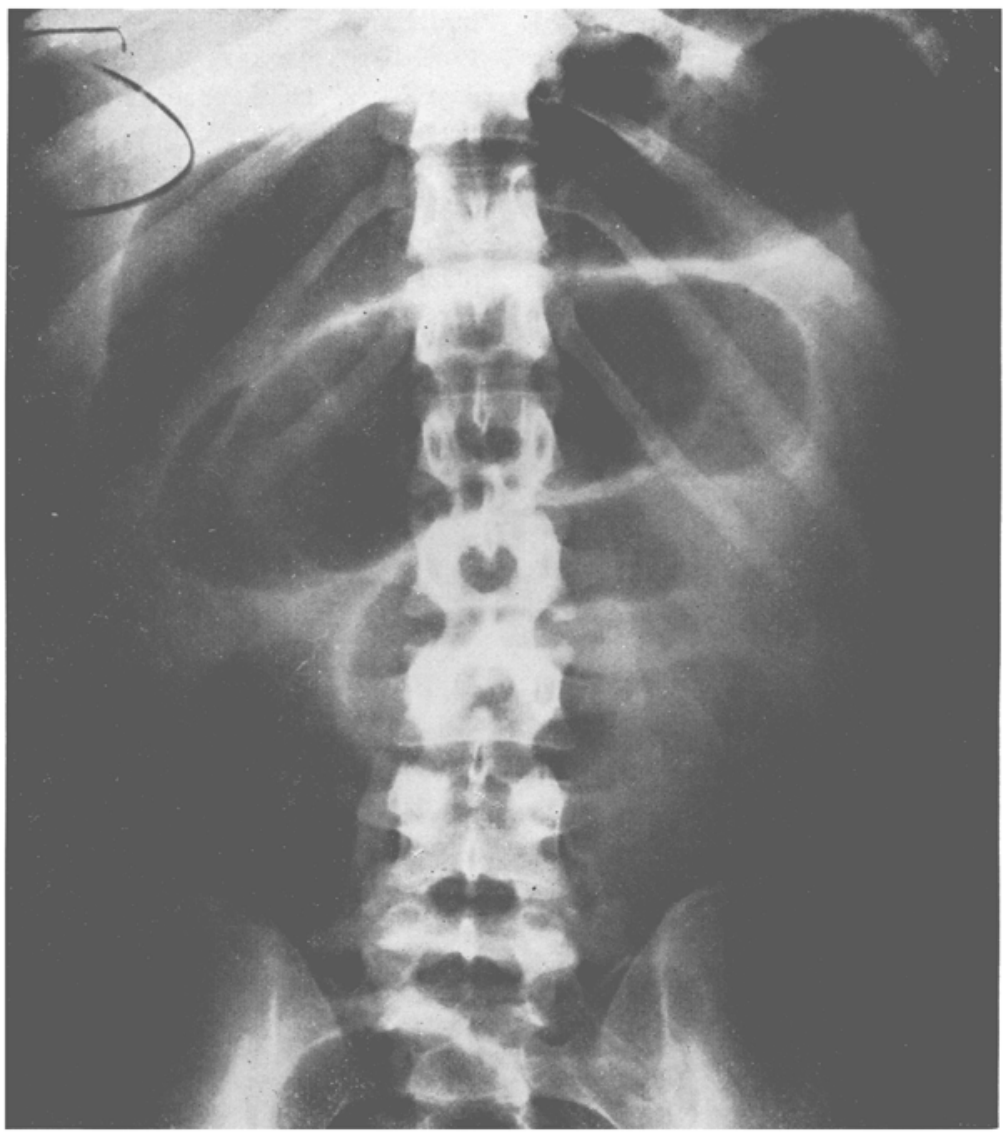

Fig 2. Dilatation of transverse colon and air in multiple loops of small bowel is shown on flat plate of abdomen.

is. In the subserosa, epithelioid giant cells were present. The colonic mucosa was interrupted by broad superficial ulcers. Examination of the small intestinal specimen revealed ulcerations into the submucosa and numerous epithelioid granulomas

After a stormy postoperative course, the patient was discharged on Azulfidine and Lomotil.* At present, he is feeling well and is a full time college student.

Case 2. SP, a 19-year-old white girl, was in excellent health until age 11, when she began to have intermittent episodes of bloody bowel movements. One year later, she was found to have a

* G. O. Searle and Co, Chicago, III. night lower quadrant mass. Cellotomy at another hospital showed gross changes of regional enteritis and a side-to-side ileotransverse colostomy was done. Approximately I year later, an abdominal wall abscess was drained.

Subsequently, an enterocutaneous fistula appeared, and she was admitted to the Lniversity of Michigan Hospital for the first time in June 1965, at the age of 14 , with the complaint of bright red blood draining from her fistula. Excision of the fistula and partial resection of the sigmoid colon was performed because of a fistulous connection. The entire ascending colon, which had previously been bypassed, was excised and an end-to-end ileotransverse colostomy was done. Histologic examination of the colon shoved chronic granulomatous 
inflammation involving the submucosa, muscularis and subserosa. Active chronic granulomatous inflammation, involving all layers of the terminal ileum, was noted. Numerous epithelioid and giant cells with a tendency to follicle formation were present.

She recovered without sequellae and was in moderately good health until Dec 1, 1965, when cramping abdominal pain, several loose brown bowel movements per day, and fever spiking to $103^{\circ}$ F occurred. She appeared acutely ill on admisson 7 days later. Her abdomen was hyperresonant to percussion and markedly tender to palpation in all quadrants. A leukocytosis of $11,000 / \mathrm{cu}$ mam with $82 \%$ polymorphonuclear leukocytes was noted. Serum electrolytes were within normal limits. A flat plate of the abdomen 1 day later showed progressive dilatation of the transverse colon and multiple

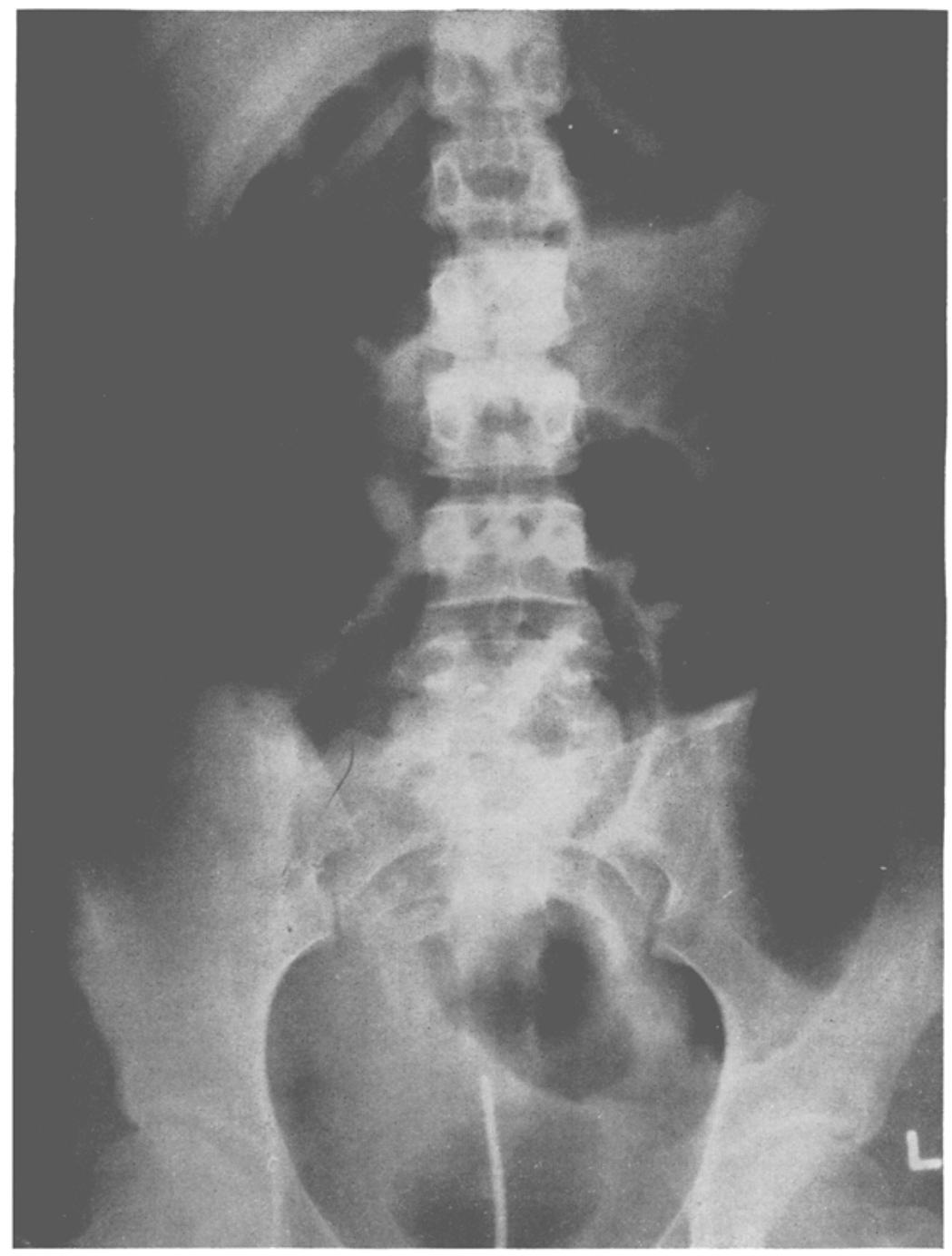

Fig 3. Dilatation of transverse colon and multiple loops of dilated small bowel is shown on flat plate of abdomen in patient with granulomatous colitis. 
loops of dilated small bowcl (Fig 3). Despite intravenous penicillin and chloramphenicol, she did not improve. Celiotomy on the third hospital day revealed no obvious site of obstruction. Fifty pex cent of the small bowel to the ileotransverse colostomy was characterized as being indurated and edematous. Numerous large lymph nodes were present in the small bowel mesentery.

Between December 1965 and February 1968, she felt well and returned to a normal life pattern. Fever $\left(101^{\circ} \mathrm{F}\right)$, cramping abdominal pain, five to six loose, watery, brown bowcl movements occurred suddenly on Feb 22, and she was admitted 2 days later. She appeared lethargic and toxic. Her abdomen was distended. Decreased bowel sounds were present. Moderate tenderness was noted in all quadrants. A flat plate of the abdomen showed scveral loops of dilated small bowel and a large dilated loop of transverse colon and splenic flexure (Fig 4). Conservative treatment of bedrest, sedation and intravenous fluids resulted in defervescence of fever and a return to normal bowel habits. $A$ barium enema revealed diffuse colitis with a loss of haustral markings and a localized area of nodularity

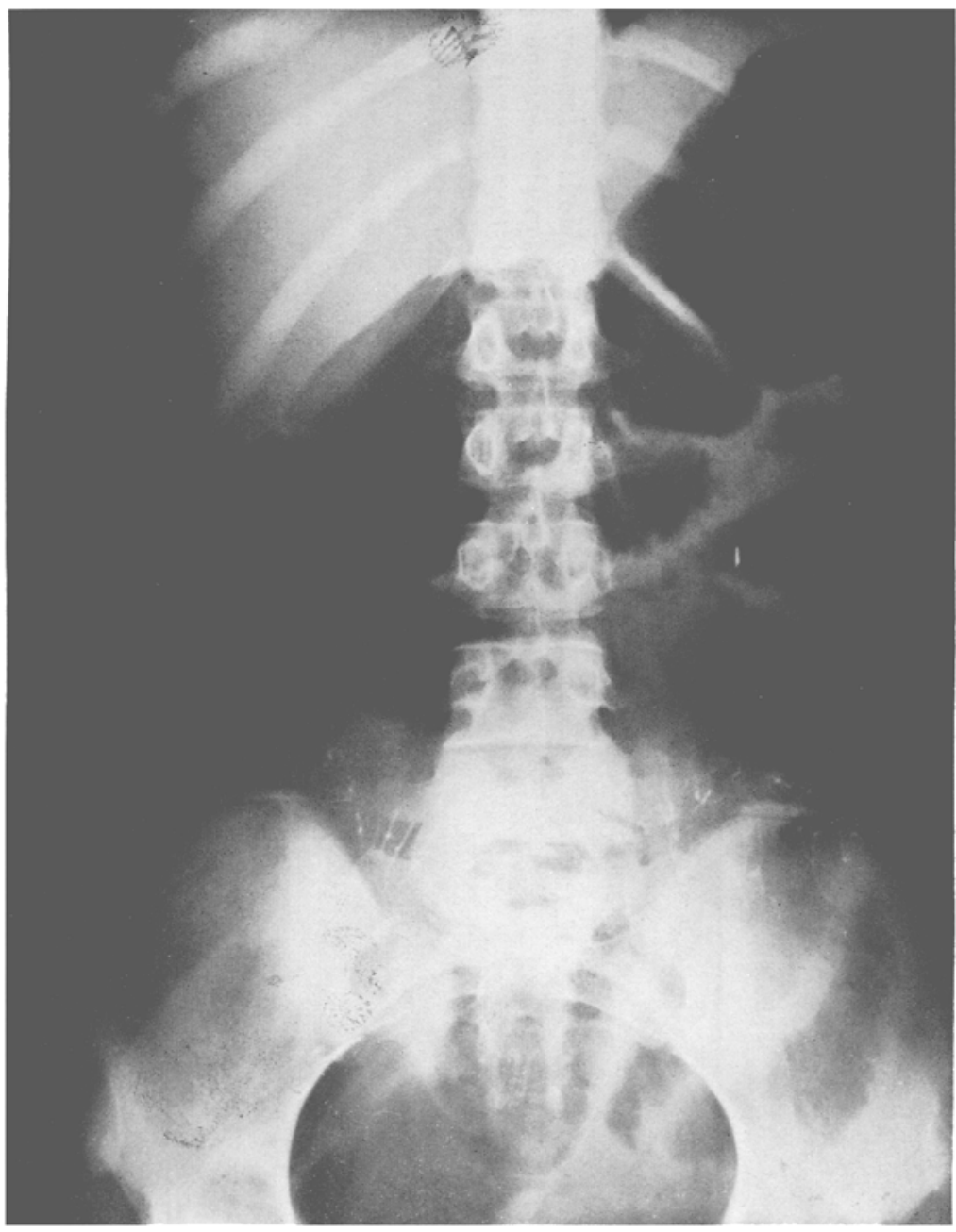

Fig 4. Toxic dilatation of transverse colon and splenic flexure in patient with granulomatous colitis. 


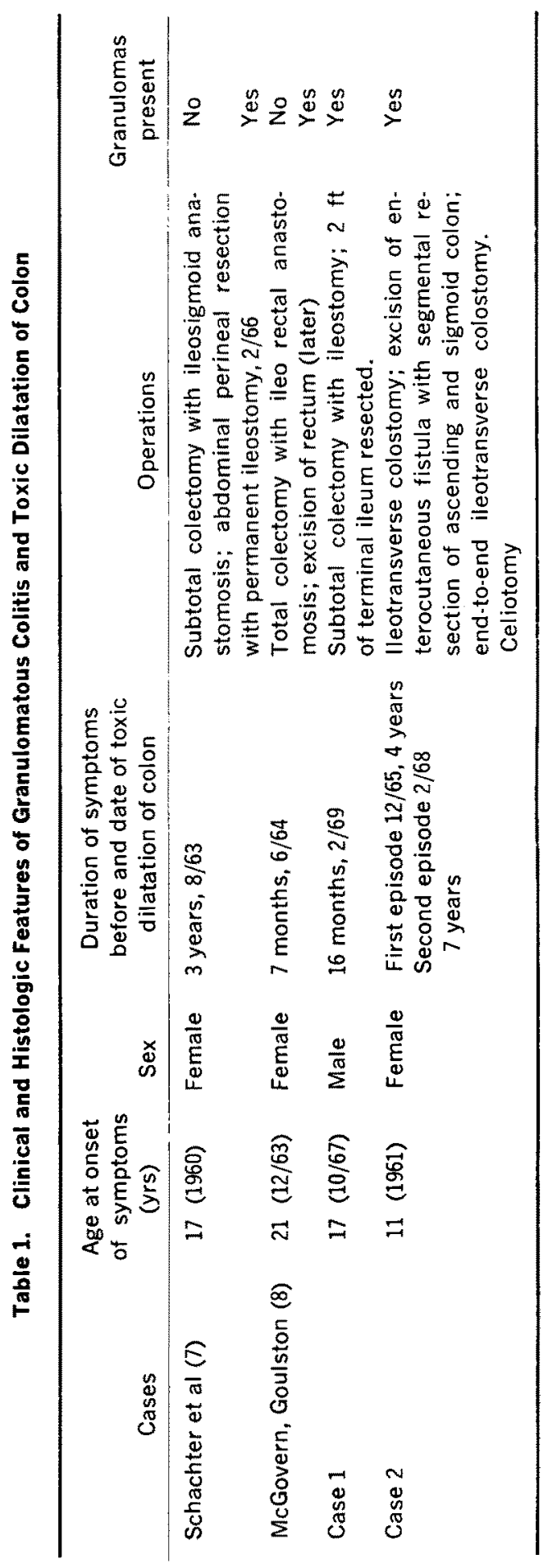




\section{GRANULOMATOUS COLITIS}

of the splenic flexure. The terminal ileum had a nodular appearance and numerous fissure ulcers (Fig 5). She continues to be asymptomatic 2 years after discharge.

\section{DISCUSSION}

The clinical diagnosis of toxic dilatation of the colon implies marked dilatation in at toxic patient. This situation is usually found in a patient with ulcerative colitis; the transverse colon being involved most often. However, toxic dilatation has recently been reported in amebic colitis (10-11). Jones and Chapman (12) defined megacolon in the transverse segment, measured in the midline, as having a diameter

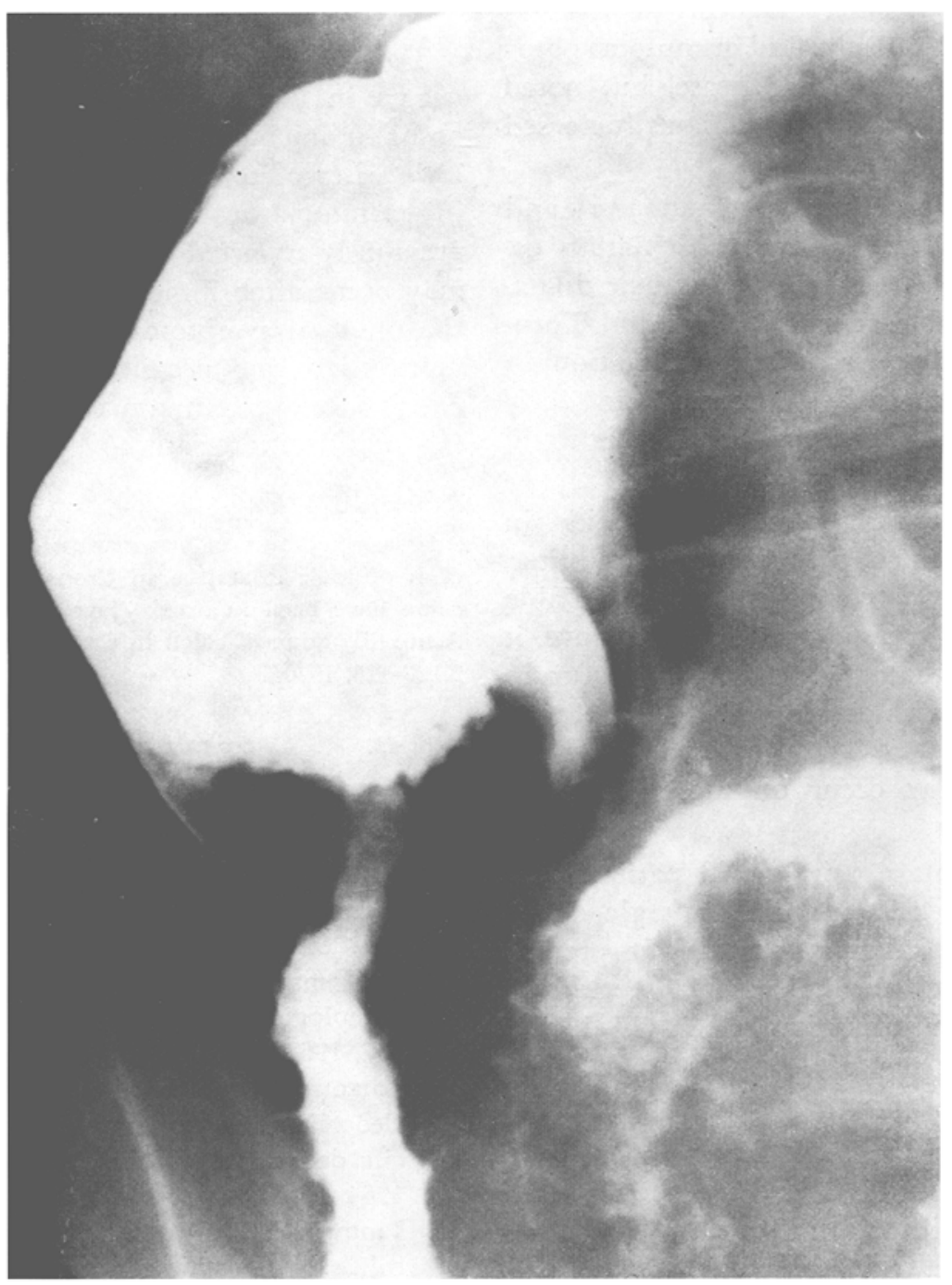

Fig 5. Numerous fissure ulcers of terminal ileum are present on barium enema examination. 
greater than $5.5 \mathrm{~cm}$ on plain abdominal $\mathrm{X}$-ray. In their study, the mean diameter in severe ulcerative colitis and megacolon was $8.2 \mathrm{~cm}$.

While inflammation is usually limited to the mucosa in ulcerative colitis, it is most often transmural in Crohn's disease. The presence of granulomas is a characteristic histologic feature. However, Meadows and Batsakis (13) do not feel that granulomas are essential for the diagnosis of Crohn's disease. They did not find granulomas dur. ing the early phase of disease, but noted that the incidence of granulomas increased with biologic chronicity.

Because of transmural inflammatory and fibrotic involvement in granulomatous colitis, it has been reasoned that toxic dilatation would not occur (8). Hawk and Turnbull (6) reasoned that toxic dilatation in granulomatous colitis occurred in early acute states before significant fibrosis could develop.

The only 2 cases of toxic dilatation in granulomatous colitis, reported in the liter. ature, are compared to our 2 cases in Table 1. Despite the reasoning described above, it is apparent that granulomas can occur in association with toxic dilatation of the colon as early as 7 months, and that toxic dilatation may occur on more than one occasion.

Toxic dilatation in our 2 patients was not precipitated by anticholinergic drugs, opiates, hypokalemia, nor did it precede barium enema, as has been reported in patients with ulcerative colitis (14-15). It is interesting to note that all of the cases listed in Table 1 were in their late teens or early twenties when toxic dilatation of the colon occurred, and that 3 of the 4 were women. The diameter of the transverse colon of Cases 1 and 2 was 7.0, 6.2 and 6.0 $\mathrm{cm}$, respectively (Fig 2, 4 and 5). In no instance was mechanical obstruction found to be the cause of the colonic dilatation.

When toxic dilatation of the colon occurs in a patient with gastrointestinal disease, the diagnosis must not be limited to ulcerative colitis; but amebic and granulomatous colitis should also be considered. It is our opinion that toxic dilatation of the colon in granulomatous colitis is more com. mon than is generally appreciated.

\section{SUMMARY}

Toxic dilatation of the colon usually occurs in ulcerative colitis, but may also occur in amebic and granulomatous colitis. Two cases of toxic dilatation of the colon in granulomatous colitis are compared to 2 previously reported cases. Toxic dilatation may occur after 7 months or 7 years from the onset of symptoms and may occur on more than one occasion. Granulomatous colitis is more common complication than is generally appreciated.

\section{Addendum}

Since acceptance of our manuscript, 5 additional cases of toxic dilatation in Crohn's disease of the colon have been reported (Javett SL, Brooke BN: Acute dilatation of colon in Crohn's disease. Lancet 2:126-128, 1970) .

\section{REFERENCES}

1. Edwards FC, Truelove SC: The course and prognosis of ulcerative colitis. III. Complications. Gut 5:1-15, 1964

2. McInerney GT, Sauer WG, Baggenstoss $\mathrm{AH}$, et al: Fulminating ulcerative colitis with marked colonic dilation, a clinicopathologic study. Gastroenterology 42:244257, 1962

3. Barron RA, Jarkowski TL, Ruel RE, et al: Ileocolitis, the importance of a more precise definition. Amer J Dig Dis 9:862-871, 1964

4. Janowitz HD, Present DH: Granulomatous colitis: pathogenic concepts. Gastroenterology $51: 802-805,1966$

5. Marshak RH, Lindner AE. Janowitz HD: 
Granulomatous ileocolitis. Gut 7:258-264, 1966

6. Hawk WA, Turnbull RB Jr: Primary ulcerative disease of the colon. Gastroenterology 51:802-805, 1966

7. Farmer RA, Hawk WA, Turnbull RB: Regional enteritis of the colon: a clinical and pathologic comparison with ulcerative colitis. Amer J Dig Dis 13:501-514, 1968

8. Schachter H, Goldstein MJ, Kirsner JB: Toxic dilation complicating Crohn's disease of the colon. Gastroenterology 53: $136-142,1967$

9. McGovern VJ, Goulston SJM: Crohn's disease of the colon. Gut 9:164-176, 1968

10. Wruble LD, Duckworth JK, Duke DD, et al: Toxic dilatation of the colon in a case of amebiasis. New Eng J Med 275:
$926-928,1966$

11. Faegenbury D, Chiat $\mathrm{H}$, Mandel PR, et al: Toxic megacolon in amebic colitis. Amer J Roentgen 99:74-76, 1967

12. Jones JH, Chapman M: Definition of megacolon in colitis. Gut 10:562-564, 1969

13. Meadows TR, Batsakis JH: Histopathological spectrum of regional enteritis. Arch Surg 87:976-981, 1963

14. Smith FW, Law DH, Nicket WF Jr, et al: Fulminant ulcerative colitis with toxic dilation of colon; medical and surgical management of eleven cases with observations regarding etiology. Gastroenterology 42:233-243, 1962

15. Roth JLA, Valdes-Dapena A, Stein GN, et al: Toxic megacolon in ulcerative colitis. Gastroenterology 37:239-255, 1959 